\title{
The FADOI (Federation of Associations of Hospital Doctors on Internal Medicine) position paper on cardiovascular prevention in the higher risk complex patients
}

Mauro Campanini, ${ }^{1}$ Giuliano Pinna, ${ }^{2}$ Roberto ardi $^{3}$ on behalf of the FADOI Cardiovascular Prevention Position Statements Group

${ }^{1}$ Internal Medicine 2, Maggiore della Carità Hospital, Novara; ${ }^{2}$ Internal Medicine, ASL AT, Asti; ${ }^{3}$ Internal Medicine, Maggiore Hospital, Bologna, Italy

\section{Members of the FADOI Cardiovascular Prevention Position Statements Group}

Paolo Pauletto, ${ }^{1}$ Domenico Panuccio, ${ }^{2}$ Paolo Verdecchia, ${ }^{3}$ Rodolfo Cavaliere, ${ }^{4}$ Fernando Gallucci, ${ }^{5}$ Giovanni Mathieu, ${ }^{6}$ Giancarlo Agnelli, ${ }^{7}$ Roberto Frediani, ${ }^{8}$ Michele Stornello, ${ }^{9}$ Dario Manfellotto, ${ }^{10}$ Giorgio Vescovo, ${ }^{11}$ Francesco Dentali, ${ }^{12}$ Antonino Mazzone, ${ }^{13}$ Luigi Magnani, ${ }^{14}$ Giuseppe Augello ${ }^{15}$

${ }^{1}$ Department of Medicine - DIMED, Padua University; Internal Medicine I, Cà Foncello Hospital, Treviso; ${ }^{2}$ Internal Medicine Complex Unit, Maggiore Hospital of Bologna; ${ }^{3}$ Complex Unit of Medicine, Assisi Hospital; ${ }^{4}$ Internal Medicine Doctor, FADOI Piemonte; ${ }^{I}$ Internal Medicine Complex Unit, A. Cardarelli AORN, Naples; ${ }^{6}$ Internal Medicine Doctor, FADOI Piemonte, past National President of FADOI; ${ }^{7}$ Internal Medicine and Stroke Unit, University of Perugia; ${ }^{8}$ Internal Medicine, ASL VCO Hospitals of Verbania and Domodossola; ${ }^{9}$ Internal Medicine, Hospital Umberto I of Syracuse; ${ }^{10}$ Internal Medicine, Hospital Fatebenefratelli, Rome; ${ }^{11}$ Internal Medicine, Hospital S. Antonio, Padua; ${ }^{12}$ Internal Medicine, Hospital Circle, Varese; ${ }^{13}$ Internal Medicine, Hospital of Legnano; ${ }^{14}$ Internal Medicine Complex Unit, Hospital of Voghera (PV); ${ }^{15}$ Internal Medicine Complex Unit, Hospital of Canicattì (AG), Italy

\begin{abstract}
Prevention is a very topical issue that any modern health system cannot ignore. The discussion about the concept of cardiovascular (CV) prevention is very wide and has been lasting for a long time. In this context, the research has never been stopped. A schematic classification of different types of prevention, as well as raised by the literature, implies some limitations, not always suitable to our complex patients. According to evidence-based medicine we should refer to the best available guidelines. Unfortunately the quality of evidence-based guidelines is far from optimal. The Federation of Associations of Hospital Doctors on Internal Medicine (FADOI) faced the problem of CV prevention in the higher risk complex patients with its experts in ischemic heart disease, heart failure, stroke, chronic kidney disease, peripheral arterial disease and diabetes mellitus, by asking the following questions: i) which are the methods of risk assessment and prognostic stratification (also with respect to the existing comorbidities)?; ii) which are the tailored actions to implement for the individual patient? For the purposes of a $\mathrm{CV}$ risk evaluation in complex patient we cannot be satisfied with a single high baseline risk strategy: we should resize

Correspondence: Roberto Nardi, via C. Pavese 16/2, 40141 Bologna, Italy.

Tel.: +39.335.8291342.

E-mail: nardidoc48@gmail.com

Key words: Cardiovascular prevention; complex patient; internal medicine. our assessment parameters to the real world, implementing a high multidimensional CV complexity risk assessment strategy, in respect of an anthropological approach to the complexity of our patients. Essentially, hospital internists are called to exercise a proactive role of experts for each single complex patient, also in $\mathrm{CV}$ prevention.
\end{abstract}

See online Appendix for additional Tables.

Received for publication: 2 October 2015.

Accepted for publication: 2 October 2015.

This work is licensed under a Creative Commons Attribution NonCommercial 3.0 License (CC BY-NC 3.0).

CCopyright M. Campanini et al., 2015

Licensee PAGEPress, Italy

Italian Journal of Medicine 2015; 9:387-404

doi:10.4081/itjm.2015.669
Not even an apple a day keeps the doctor away? ${ }^{1}$

\section{Presentation: this is not a simple matter}

Atherosclerosis is a chronic, multifactorial disease that affects the arteries of large and medium caliber, characterized by an intimal focal injury, protruding inside the arterial lumen and causing its progressive re- 
striction. ${ }^{2}$ Atherosclerotic lesions have generally a focal distribution within individual arteries and affect multiple arterial branches. ${ }^{3}$ Elastic and muscular arteries, both of medium and large caliber, represent the most frequent seats affected by the atherogenic process. Main localizations, by frequency, are the distal portion of the abdominal aorta, the coronary arteries, the lower extremities (iliac, femoral and popliteal) arteries, the descending portion of the thoracic aorta, the carotid, vertebral arteries and the Willis circle. While intimal lesions begin to early develop during the first decades of life, clinical manifestations appear in adulthood, when there is a significant impairment of blood flow or in the presence of complications. Myocardial and cerebral infarction, aortic aneurysms and peripheral arterial disease are some of the most frequent clinical consequences of atherosclerosis. ${ }^{4}$ The objectives of Medicine are to promote and maintain health, or to restore it when compromised, in order to minimize suffering and disability of our patients. Cardiovascular diseases $(\mathrm{CV})$ are the leading causes of deaths in Europe and worldwide. Also in Italy they represent one of the major public health problems, with massive implications on economic resources, as important causes of mortality, morbidity and disability. The most frequent $\mathrm{CV}$ pathologies, ranging from the so-called chronic non-communicable diseases are, specifically, ischemic heart disease (acute myocardial infarction and angina pectoris), cerebral-vascular disease (ischemic and hemorrhagic stroke), peripheral artery disease, chronic kidney disease, plus some morbid conditions burdened by a high prevalence and incidence, such as diabetes mellitus, metabolic diseases and heart failure. Strategies addressed to correcting the risk factors for a disease within a population are basically three: i) addressed to the whole population (community strategy); ii) targeted at individuals characterized by high levels of a single risk factor; iii) targeted at individuals with high levels of overall risk (i.e., a mix of various levels of exposure to different risk factors). ${ }^{5}$ Differentiating between primordial, primary (avoiding the occurrence of the disease in healthy people), secondary, and tertiary prevention (avoid the progression of the disease and complications in the sick people) is not an obvious or simple concept. It requires a definition upon the notion of disease that allows distinguishing between healthy and sick people. These categories are arbitrary and are used in order to systematize a complex matter for the organization of the health system, but possible overlaps between both of them cannot be ruled out. ${ }^{6}$ The concept of primary and secondary prevention does not highlight that atherosclerosis is an ongoing, evolving process: the subclinical organ damage, rather than the overt event, should be the reference designed to protect the patient earlier on detection of risk factors. The distinction between these situations was tradition- ally defined by the presence or absence of major $\mathrm{CV}$ events with clinically explicit symptoms (such as chest pain, focal neurological symptoms, claudication, etc.). Today, thanks also to non-invasive diagnostic imaging, it is possible to detect some organ damage and/or subclinical, often still asymptomatic, pathological situations, ranging from the presence of an intima-media thickening to the detection of the alteration of the pressure-ankle/arm ratio, of coronary calcifications and/or of atherosclerotic plaques or micro-albuminuria. ${ }^{7}$ The introduction of several diagnostic techniques has facilitated the ability to make a diagnosis of the disease, even in the absence of overt symptoms. Subclinical disease is an issue of great epidemiological importance in internal medicine (IM): ${ }^{8}$ we must have the ability to research the iceberg, underlying diseases, on the basis of an overall assessment. For those reasons, the priorities of assessment are suggested in the literature according to four levels: i) patients with a diagnosed disease; ii) asymptomatic individuals at high risk for CV mortality; iii) first-degree relatives of patients with premature $\mathrm{CV}$ disease; and iv) other patients encountered in routine clinical practice. ${ }^{9}$ Hence, we have the need for prevention measures based on the individual assessment of $C V$ risk of each single patient, therefore with interventions on multiple risk factors and treatment of all associated clinical conditions. The strategy should be substantially to treat the risk level, rather than the risk factor.$^{10}$ The American Heart Association (AHA), the American College of Cardiology (ACC), the American College of Chest Physicians (ACCP) and the Canadian Cardiovascular Society (CCS) have recently emphasized the focus on CV prevention, addressing the issue in terms of lifestyle, considering the presence of overweight and/or obesity and hypercholesterolemia in adults, and on the importance of antithrombotic therapy. To these were added the European Atherosclerosis Society (EAS) and the European Society of Cardiology (ESC) guidelines, with the emerging recommendations about the importance of CV risk stratification and the reduction of low-density lipoprotein cholesterol (LDL-c) in primary and secondary prevention. ${ }^{11-17}$ Specifically, they identified four categories of people at risk, requiring specific attention by doctors for the $\mathrm{CV}$ prevention: i) subjects with atherosclerotic $\mathrm{CV}$ clinically apparent disease; ii) subjects with LDL cholesterol levels $>190 \mathrm{mg} / \mathrm{dL}$ and with familial hypercholesterolemia; iii) diabetics aged 40-75 years, with LDL cholesterol levels between 70 and $189 \mathrm{mg} / \mathrm{dL}$ and without evidence of atherosclerotic cardiovascular disease; iv) individuals without evidence of CV disease or diabetes, but whose LDL cholesterol levels are between 70 and $189 \mathrm{mg} / \mathrm{dL}$ and 10 -year CV atherosclerotic risk is above $7.5 \% \cdot{ }^{13}$ In IM the management of patients at higher $\mathrm{CV}$ risk or with established $\mathrm{CV}$ disease can be particularly problematic, 
owing to the complexity of patients, strongly influencing the doctor's decision making process. According to a recent cross-sectional study in subjects with coronary heart disease aged over 45 years, ${ }^{18}$ we have to consider different factors, such as: i) the co-existence of other chronic diseases: osteoarthritis (in 56.7\% of the subjects examined), heart failure (29\%), chronic obstructive pulmonary disease (COPD), diabetes mellitus (in 25\%), stroke (13.8\%); ii) alteration of laboratory data and the presence of factors suggestive of clinical complexity: reduced glomerular filtration rate (in $24.4 \%$ of patients), anemia (in $10.1 \%$ ), abnormal transaminases (in 5.9\%), taking more than four drugs (in $54.5 \%$ of cases), urinary incontinence (in $48.6 \%$ ), dizziness or falls (in 34.8\%), oral anticoagulant therapy (in 10.2\%); iii) general factors indicative of an altered state of health: cognitive impairment (found in 29.9\%), difficult moving (40.4\% of cases), lack of vision or hearing (in 16.7 and $17.9 \%$ of cases, respectively). Patients in IM are old or very old (mean age 78.2 years), with high number of comorbidities ( $\geq 3$ diseases) and with 6 or more concomitant treatments. Only $35 \%$ of patients are completely autonomous and at least 33\% of the patients are bedridden. Over $80 \%$ needs some support at home for the care and treatment, with almost $50 \%$ helping some continuously care need. ${ }^{19}$ Since 1996 the Federation of Associations of Hospital Doctors on Internal Medicine (FADOI) deals with CV risk. In two studies (FAPOI-1-1996 and FAPOI-2-1999) in the analysis of comparison of the treatment of patients at risk of $\mathrm{CV}$ discharged from wards of Internal Medicine, on 6450 (235 wards) and 8133 patients (345 wards) respectively emerged a greater propensity to the use of statins, in front of a still apparent under-treatment of some $\mathrm{CV}$ risk conditions, such as hypertension, especially in women. ${ }^{20}$ In the NIMEC (National Internal Medicine Equivalent/Complex C-V-@Risk) study, ${ }^{21}$ performed on 902 subjects $[457 \mathrm{M}, 445 \mathrm{~F}$, mean age 72 years, body mass index $26.7 \mathrm{~kg} / \mathrm{m}^{2}$ (range 26.3 to $27.1 \mathrm{~kg} / \mathrm{m}^{2}$ )] of the total 1316 patients hospitalized in wards of Internal Medicine, the prevalence of metabolic syndrome (MS) according to the Adult Treatment Panel III (ATP III) criteria was 45.3\% [95\% confidence interval (CI): 41.6 to 49.1$]$ and $38.6 \%$ (95\% CI: 34.9 to 42.3 ), according to the International Diabetes Federation (IDF) criteria. The epidemiological data by the joint FADOI-SIMI (Società Italiana di Medicina Interna - Italian Association of Internal Medicine) analysis on the day a meter for life, carried out on 1877 people in 2015 on the out-hospital national setting, considering the measurement of waist circumference, blood pressure and blood sugar levels, highlighted an overall prevalence of MS in $17.4 \%$ of males and $11.4 \%$ of females. ${ }^{22}$ Arterial hypertension is one of the most frequent findings in patients admitted in IM wards. ${ }^{23}$ In spite the fact that the evidence to support use of most surrogate outcomes for policy making is weak, blood pressure is viewed as one of the few surrogate outcomes with a sufficiently robust evidence base to guide policy. ${ }^{24,25}$ In complex patients, comorbidities involve significant interrelationships between common risk factors, whose control may facilitate the management. ${ }^{26} \mathrm{~A}$ striking example is represented by COPD, in which increased CV morbidity and mortality are proven. ${ }^{27,28}$ Moreover we have to consider possible inequalities in the access to care (a tool introduced about is the Townsend deprivation score), ${ }^{29}$ the associations and clusters of diseases, ${ }^{30}$ which can affect the prognosis of patients, such as, for example, in the case of atrial fibrillation. Comorbidities may result in an increased CV risk not only for the potential risk factors common to other diseases, such as smoking, obesity, hypertension and alcohol abuse, but also for the pathophysiology of the disease itself. CV risk may be underestimated in patients with some comorbidities or treatment for other diseases. ${ }^{31}$ Several studies investigated the association between atherosclerotic disease and some infectious microorganisms, such as hepatitis A virus, ${ }^{32}$ herpes simplex virus, ${ }^{33}$ Chlamydia pneumoniae ${ }^{34}$ and HIV; ${ }^{35}$ however, not only the precise mechanisms remain unclear and a controversy also exists over whether such an association really exists. HIV, for example, regardless of treatment, could amplify the pro-atherogenic process. ${ }^{36}$ In addition, several drugs may be involved in atherogenesis, such as highly active antiretroviral therapy, corticosteroids, acitretin, and cyclosporine. Similarly, also the hepatitis C virus (HCV) infection may result in increased $\mathrm{CV}$ risk $^{37,38}$ and a higher incidence of coronary events in HCV- seropositive patients was highlighted, but with a much higher incidence in patients with detectable HCV RNA than those with only HCV positivity, just to legitimate the doubt that the lipid profile cannot always be an useful tool in CV risk stratification in patients with $\mathrm{HCV}$ infection. ${ }^{39}$ Moreover, we should not underestimate the role of inflammation, with pro-inflammatory cytokines and leptin as important agents in the pathogenesis of atherosclerosis ${ }^{40}$ These mechanisms are shared with several other conditions, apparently unrelated to each other, but with similar pathogenic ways, such to define a specific framework disease state [the so-called immune mediated inflammatory disorders (IMIDs)], which in the general population may reach a prevalence of up to $7.5 \%$. The spectrum of chronic diseases IMID-related is very broad: allergy, asthma, Beçhet's disease, COPD, Crohn's disease, ulcerative colitis, multiple sclerosis, psoriasis, rheumatoid arthritis, spondylo-arthropathies, sarcoidosis, uveitis, vasculitis, and so on. ${ }^{41}$ In the concept of a comprehensive approach to IM care we believe that in complex patients, when the risk/benefit of preventive and therapeutic interventions may be influenced by comorbidities and 
Questions submitted to the FADOI experts

The questions asked to the FADOI experts for the $\mathrm{CV}$ prevention in the higher risk complex patients in each individual pathology (considering previous and/or the clinical evidence of ischemic heart disease, ${ }^{63}$ heart failure, stroke, chronic kidney disease, peripheral arterial disease, diabetes mellitus) are the following:

i) which methods of risk assessment and prognostic stratification (also with respect to the existing comorbidities)?;

ii) which actions are to implement, tailored for the individual patient?

\section{Answers to the raised questions by the interviewed experts internists for every single disease}

\section{Ischemic heart disease}

\section{Risk assessment and prognostic stratification}

Over $50 \%$ of the reduction in mortality from coronary heart disease (CHD) is due to the reduction in risk factors, as well as to more appropriate non-pharmacological and pharmacological treatments. The EUROASPIRE III study, performed on 8966 patients recruited from 22 European countries, however, found that only a small portion of subjects show an effective and satisfactory control of $\mathrm{CV}$ risk factors. ${ }^{64}$

\section{Recommendations in patients with chronic ischemic heart disease}

Due to the complexity of our patients we just limit our recommendations to some schematic criteria:

- Behavior strategies (educational/psychological interventions/changes in lifestyles) ${ }^{65}$

- Avoid smoking ${ }^{66}$

- Healthy diet and physical activity; ${ }^{67}$

- Body weight (weight reduction in obese or overweight people); 68

- Blood arterial pressure, ${ }^{69}$ in particular we suggest to: i) consider antihypertensive strategies; ii) avoid diuretics and $\beta$-blockers in patients at high risk for developing diabetes mellitus; $;{ }^{70}$ iii) recommend ACE-inhibitors (ACEi) and angiotensin II receptor blockers (ARBs) for patients with diabetes $^{71}$ and antiplatelet drugs in hypertensive patients: ${ }^{72}$

- Lipids (cholesterol reduction) $;^{73}$

- Antithrombotic agents (careful evaluation of antithrombotic drugs administration) $;{ }^{74}$

- Blood glucose control, HbAlc should be reduced to levels $<7.0 \%,{ }^{75}$ whilst metformin should be the drug of first choice, unless contraindicated. ${ }^{76}$ 
Which are the methods of risk assessment and prognostic stratification (also with respect to the existing comorbidities)?

Risk assessment and prognostic stratification in the prevention of cardio-vascular system in patients with overt ischemic heart disease has to be made on the basis of an overall assessment, with a careful evaluation of the associated co-morbidities, even if underlying: i) for the CV risk assessment in patients with CHD lifestyle habits, voluptuary attitudes and physical activity, weight and blood pressure control, drugs taken and adherence to prescribed medications are particularly important; ii) existing comorbidities (overt diabetes mellitus, kidney failure - also if concealed -, equivalent of $\mathrm{CV}$ and/or associated complex conditions) should be considered; iii) all therapies carried out and their connected adverse reactions (hypoglycemia, hypotension, bleeding, worsening of renal function, etc.) should be considered; iv) in the antithrombotic treatment, both the risk of thrombosis and bleeding for each individual patient should be properly reasoned; v) when assessing the risk and prognostic stratification we should clearly identify, also for the purpose of continuity and coordination of care, all the patients at higher CV risk, deserving them a dedicated preventive control.

\section{Which tailored actions shall be implemented for the individual patient?}

Actions that should be implemented in CHD patients are summarized in Table 1.

\section{Heart failure}

\section{Heart failure definition}

Heart failure (HF) is a complex clinical syndrome caused by a structural and/or functional abnormality, cause of ventricular filling and/or its ejection damage, leading to the loss of the heart ability to supply adequate amounts of blood to metabolic tissues needs, if not by increasing the left ventricular end-diastolic pressure. $^{77,78}$

\section{Ejection fraction and heart failure classification}

The emphasis on ejection fraction (EF) in the classification of $\mathrm{HF}$ is related to its relationship with some patient's characteristics (comorbidities, prognostic factors and their response to therapy). Patients enrolled in most trials are selected on the basis of this parameter. HF classification according to EF is reported by Yancy et al. ${ }^{79}$

Table 1. Actions to implement in the individual patient.

\begin{tabular}{|c|c|c|}
\hline \multicolumn{2}{|l|}{ Actions } & Class \\
\hline \multicolumn{2}{|l|}{ Educational/behavioral strategies } & 1 \\
\hline \multicolumn{2}{|l|}{ Abolishing all exposure to smoking } & 1 \\
\hline \multicolumn{2}{|c|}{ Low in saturated fat, salt, relatively rich with fish diet, red wine $(20 \mathrm{~g} /$ day in men $10 \mathrm{~g} /$ day in women $)$} & 1 \\
\hline \multicolumn{2}{|c|}{ Physical activity ( 3 at least 0 min 3 times per week) } & 1 \\
\hline \multicolumn{2}{|l|}{ Weight reduction } & 1 \\
\hline \multicolumn{2}{|l|}{ Blood pressure reduction (by any drug) } & 1 \\
\hline \multicolumn{2}{|l|}{ Lowering LDL cholesterol $<70 \mathrm{mg} / \mathrm{dL}$} & 1 \\
\hline \multicolumn{2}{|c|}{ Antiplatelet agents (double association only for the first 12 months), then ASA } & 1 \\
\hline Blood glucose control & $\begin{array}{l}\text { HbAlc }<7.0 \% \\
\text { Metformin as the drug of choice } \\
\text { Avoid weight gain and hypoglycemia }\end{array}$ & $\begin{array}{c}1 \\
\text { IIa } \\
\text { I }\end{array}$ \\
\hline \multicolumn{3}{|c|}{$\begin{array}{l}\text { All patients requiring hospitalization or invasive procedure after an acute coronary event should participate in a } \\
\text { rehabilitation program in order to improve the prognosis through changes in lifestyle and treatment adherence }\end{array}$} \\
\hline \multirow[t]{3}{*}{ Individual patients with associated diseases } & Arthritis/osteoarthritis & $\begin{array}{l}\text { NSAID: } \\
\text { increased coronary risk }\end{array}$ \\
\hline & COPD & $\begin{array}{l}\mathrm{BB}, \mathrm{ARBs} \text {, statins, some doubt } \\
\text { about anticholinergics }\end{array}$ \\
\hline & Depression & $\begin{array}{l}\text { Independent correlations } \\
\text { with primary and secondary } \\
\text { heart disease }\end{array}$ \\
\hline
\end{tabular}

LDL, low-density lipoprotein; ASA, acetylsalicylic acid; NSAID, non-steroidal anti-inflammatory drug; COPD, chronic obstructive pulmonary disease; BB, $\beta$-blockers; ARBs, angiotensin II receptor blockers. 


\section{Heart failure epidemiology}

The prevalence of HF among the general population is between $2 \%$ and $3 \%$, with a marked increase after the age of 75 (with percentages ranging from 10 to $20 \%$ ); over 60 years $10 \%$ of male subjects and $6 \%$ of females present a clinical picture of HF. In European countries, HF accounts for $5 \%$ of the causes of hospitalization and high health service costs (approximately $2 \%$ of health spending), owing to hospital stays, emergency department visits and repeated medical consultations.

\section{Which are the methods of risk assessment and prognostic stratification (also with respect to the existing comorbidities)?}

The New York Heart Association (NYHA) Functional Classification provides a simple way of classifying the extent of heart failure (Appendix Table 1). ${ }^{80}$

Despite progress in therapy, the overall prognosis of HF is still unfavorable, with 5-year mortality after diagnosis quite high (approximately $50 \%$ ), similar to that of many cancers. Appendix Table 2 lists the most frequent clinical conditions associated with a worse prognosis in $\mathrm{HF}$ as several issues.

\section{Which tailored actions shall be implemented for the individual patient?}

Some actions are essential to ensure a proper care in heart failure:

- HF patients have to be aware of their condition through an educational program, to help them in improving self-care and their quality of life, mostly for preventing acute exacerbations and improving the prognosis, under the supervision by general practitioners.

- Non-pharmacological interventions in dietary and behavioral measure are essential, such as a lower salt diet, reducing fluid intake, physical training and abolition of cigarette smoking: i) a dietary regime that provides an intake of $1.5 \mathrm{~g}$ /day of sodium for the majority of patients with HF in stage A and B is recommended; for patients belonging to stages $\mathrm{C}$ and $\mathrm{D}$, although in absence of currently sufficient information in literature, a sodium consumption lower than $3 \mathrm{~g}$ /day may improve symptoms; ii) in the patients with severe HF it should also be encouraged the reduction of daily fluid intake ( $\max 1.5-2 \mathrm{~L} /$ day); the body weight water restriction $(30 \mathrm{~mL} / \mathrm{kg}$ body weight or 35 $\mathrm{mL} / \mathrm{kg}$ if body weight exceeds $85 \mathrm{~kg}$ ) can reduce their thirst.

- Special attention must be paid to co-morbidities, such as sleep disorders (OSAS), obesity (but even to a low body mass index up to cachexia) and depression.

- We should also carefully assess the side effects of some commonly used drugs [such as non-steroidal anti-inflammatory drugs (NSAIDs)].

- A proper social support should be guaranteed and an active life should be encouraged, by growing social relationships.

- A flu and pneumococcal vaccine has to be provided.

- Highest attention should be paid to any early possible worsening of symptoms and objective signs, highlighted by the patient himself, his family or caregivers or by monitoring some selected data, even with computerized tools.

\section{Management of heart failure: \\ hospital discharge information}

Hospital discharge information and communication tools are crucial for the continuity of care: they are considered as main indicators of the quality of HF process management. Improving information transfer from hospital to primary care requires some important steps such as: i) describing etiological diagnosis, associated comorbidities, risk stratification; ii) explaining laboratory data, instrumental tests, specialist consultations; ii) explaining all the drugs prescribed during hospitalization and medications recommended after discharge; iii) monitoring and pursuing optimal dry weight heart rate, blood pressure; iv) defining the follow-up program of a short term (7-10 days) and in the medium-long term; v) supporting nursing and social care at home needed; vi) explaining some preferential telephone contacts provided; vii) providing an accurate patient and family education program, for the self-management (including weight measurement and red flags alerts).

\section{Management of heart failure pharmacological interventions}

Pharmacological interventions are very important in improving the symptoms related to congestion and/or low flow rate, in preventing hospital readmissions and reducing mortality. In patients with HF with reduced left ventricular ejection fraction (LVEF), ACEi or ARBs, $\beta$-blockers and anti-aldosterone agents are very useful in changing the course and prognosis of HF. The treatment should be initiated, with the majority of drugs, at low doses, with subsequent progressive and gradual titration up to the maximum dosage, as indicated by the guidelines and well tolerated by the patient. A flexible scheme in the assumption of diuretics (better if self-managed) would be used to reduce signs and symptoms of congestion. A lot of attention must be paid to drug interactions and their effects (for instance, on electrolyte balance), especially in the presence of some possible comorbidities (such as, renal failure). Until now, in HF with preserved left ventricular ejection fraction no one-drug treatment has proven to reduce morbidity and mortal- 
ity. Particular care should be used in administering diuretics to avoid a critical decrease in pre-load and in reducing heart rate, to facilitate the ventricular filling, and in ensuring the proper treatment of arterial hypertension and ischemic heart disease.

End stage heart failure: cardiac resynchronisation therapy, implantable cardioverter defibrillator, ventricular assist devices, heart transplantation

Selection and management of ventricular assist device or of procedures of cardiac surgery is not among the duties of internal medicine doctors, who, however, must know their indications, selecting when seek the necessary specialist advice. ${ }^{81-83}$

\section{Cardiac resynchronisation therapy}

In patients with reduced LV function ( $\mathrm{EF} \leqslant 35 \%$ ), sinus rhythm, left bundle branch block or echocardiographic signs of ventricular dyssynchrony and QRS width $\geqslant 120 \mathrm{~ms}$, who remain symptomatic (NYHA IIIIV) despite optimal medical treatment, cardiac resynchronisation therapy by using biventricular pacing improves symptoms and exercise capacity while decreasing hospitalisations and mortality.

\section{Implantable cardioverter defibrillator}

In primary prevention of sudden cardiac death (SCD) in heart failure patients with optimal pharmacological treatment, implantable cardioverter defibrillator (ICD) therapy is indicated in selected patients with LVEF $-30 \%$ after myocardial infarction ( $>40$ days) and in patients with ischemic and non-ischemic heart failure (NYHA class II-III) with LVEF $-35 \%$ to reduce mortality. For secondary prevention of SCD, ICD implantation has been shown to reduce mortality in cardiac arrest survivors and in patients with sustained symptomatic ventricular tachyarrhythmias.

\section{Ventricular assist device}

One of the most promising new alternatives to heart transplantation is the use of ventricular assist devices, ${ }^{84}$ both as a bridge to transplantation and permanent support.

\section{Heart transplantation}

The surgical approach for the treatment of end stage heart failure improves exercise capacity, quality of life, and survival compared with conventional treatment. Indications for heart transplantation are: general conditions yet fair, severe symptoms despite optimized therapy; poor prognosis on the short term; absence of therapeutic alternatives (i.e., severe symptoms of ischemia that constantly limit routine activity and are not amenable to coronary artery bypass surgery or percutaneous coronary intervention); he- modynamic compromise due to heart failure, recurrent symptomatic ventricular arrhythmias refractory to all therapeutic modalities absence of contraindications and patient's motivation after information. Contraindications for heart transplant are: comorbidity (cancer treated in the previous 5 years, kidney or liver failure, multi-organ systemic disease, systemic infection, psychiatric illness); fixed elevated pulmonary vascular resistances and alcohol or drug current abuse.

\section{Stroke and cerebral vascular accidents}

Stroke is the second leading cause of death in the world (the third in the USA) and the main cause of disability. There are about 500 ischemic attacks and 2400 new strokes per million inhabitants/year. One third of new-onset stroke patients die each year, while just under half lose their independence. Primary and secondary prevention are strategic keys to preventing stroke and reducing significantly its recurrence. ${ }^{85}$

\section{Early secondary prevention: transient ischemic attack}

Transient ischemic attack (TIA) is associated with higher risk of incident recurrent and premature stroke since by the first $24 \mathrm{~h}$ until the thirtieth day. Therefore, secondary prevention after a TIA has to be initiated immediately.

\section{Chronic secondary prevention: a strict control of all risk factors is necessary}

\section{High blood pressure}

Arterial hypertension and age are the most powerful risk factors for stroke and lowering high blood pressure (BP) is mandatory, regardless of the used medications. Moreover, we have to recognize that some drugs are more effective than others, at least in secondary prevention: diuretics and calcium channel blockers seem to be more effective drugs.

\section{Use of estrogens}

The estrogen replacement therapy in postmenopausal women has not proved to be effective in preventing either primary or secondary $\mathrm{CV}$ prevention. The use of estrogen showed a worsening trend, but not significant, toward stroke recurrence.

\section{Lipid metabolism}

If the relationship between dyslipidemia and coronary artery disease (CAD) is widely recognized, it remains controversial for stroke.

\section{The treatment of carotid artery disease}

Carotid endarterectomy (CEA): There is an evidence-based consensus in asserting that in patients with 
TIA or minor stroke and with stenosis of $70 \%$ or greater, the endarterectomy is the best option for the prevention of recurrent stroke. Conversely, surgical approach is not useful in stenosis lower than $50 \%$, while for those between $50-69 \%$ and with ipsilateral symptoms the endarterectomy outcomes depend on the risk stratification of the patient. Finally, it was observed that the treatments achieved within two weeks from the acute episode have a significant preventive effect greater than those later ones especially in women.

Angioplasty and carotid stenting: Carotid stenting is an appealing, less invasive alternative to carotid endarterectomy, emerged as an important mode of therapy for high-risk patients with symptomatic high-grade stenosis. ${ }^{86}$ Angioplasty/stenting are now gaining more and more acceptance, mostly in case of inability to tolerate general anesthesia for CEA, history of damage to the contralateral vocal cord (previous CEA or neck surgery), previous neck surgery on the ipsilateral side, restenosis after CEA ${ }^{87}$

Antiplatelet agents: The role of platelets in the pathogenesis of atherothrombosis is now well known. The effectiveness of antiplatelet therapy for secondary prevention of stroke has been demonstrated with randomized trials and meta-analysis. Acetylsalicylic acid (ASA), ticlopidine, dipyridamole, cilostazol and trifusal have been studied for their peculiarities of antiplatelet drugs in the secondary prevention of stroke. The most effective results are obtained with ASA and clopidogre; cilostazol and triflusal have given results similar to ASA.

Combination therapies: Dipyridamole plus ASA was effective in the secondary prevention of stroke or death in the long term, but with increased risk of major bleeding.

Oral anticoagulants: To date, the anticoagulant treatment does not have significant advantages over antiplatelet agents in the prevention of non-cardioembolic stroke, with the danger on the contrary of major bleeding: antiplatelet therapy continues to be the first choice therapy for non-cardioembolic stroke or TIA.

Terutroban: A study with terutroban, specific antagonist receptor of thromboxane A2, was stopped for futile results from the Data Monitoring Committee.

Conclusions: Secondary prevention after TIA or stroke event, it is crucial to address our intervention in preventing further damages that this could still cause. Strategies include the approach to CV risk factors such as blood pressure, diabetes, dyslipidemia, smoking, obesity, sedentary lifestyle. Antiplatelet therapy and more specific interventions such as the carotid revascularization may play a crucial role.

Which are the methods of risk assessment and prognostic stratification (also with respect to the existing comorbidities)?

Several prognostic scores for prediction of early stroke risk after TIA have been developed during the last decade. There are two types of prognostic scores: clinical and clinical-plus scores. The former is based on clinical predictors that are either baseline patient's features or TIA characteristics and include the California score, $\mathrm{ABCD}$ score, and $\mathrm{ABCD}^{2}$ score. Clinical-plus scores provide risk assessment based on imaging and other diagnostic test findings in addition to clinical predictors: they include the clinical and imaging-based predictive score (CIP), $\mathrm{ABCD}^{2}$ plus imaging score $\left(\mathrm{ABCD}^{2}-\mathrm{I}\right), \mathrm{ABCD}^{2}$ plus dual TIA and imaging score $\left(\mathrm{ABCD}^{3}-\mathrm{I}\right)$ and recurrence risk estimator score (RRE). The $\mathrm{ABCD}^{2}$ score is one of the most widely used clinical scores: it was generated as clinical score from a combined dataset from two prior scores (California and ABCD score). ${ }^{88}$ The risk assessment based on $\mathrm{ABCD}^{2}$ score is reported in Appendix Table 3.

\section{Which tailored actions shall be implemented for the individual patient?}

The following actions are recommendable:

- Hospital admission, if indicated according to the $\mathrm{ABCD}^{2}$ score.

- Early secondary prevention: i) TIA: $\mathrm{ABCD}^{2}$ score assessment and early anti-platelet agents treatment; ii) atherothrombotic stroke: anti-platelet agents treatment within $48 \mathrm{~h}$; iii) early carotid thromboendarterectomy [thrombus endarterectomy (TEA) or CEA] within 2 weeks after the acute event can lead to better results, mostly in women. ${ }^{89}$

- Chronic secondary prevention: i) control of CV risk factors (hypertension, dyslipidemia, diabetes, smoking, use of estrogen); ii) antiplatelet therapy; iii) TEA.

- Medical therapy: i) ASA 50-325 mg (100 mg according to experts); clopidogrel $75 \mathrm{mg}$; ii) ASA $(25 \mathrm{mg})$ and dipyridamole $(200 \mathrm{mg})$ twice daily.

\section{Chronic kidney disease}

Cardiovascular diseases are frequently associated with chronic kidney disease (CKD), ${ }^{90}$ in which the CV morbidity and mortality significantly increase. In Italy there are currently about 50,000 patients on hemodialysis, 4000 patients on peritoneal dialysis, 20,000 kidney transplanted, 10,000 incident patients on dialysis, five million suffering from CKD, 15 million of hypertensive and 8 million diabetic patients with possible kidney damage.

Mortality from CV disease is 10 to 30 times higher in dialyzed patients than in the general population.

Therefore, patients with CKD should be considered as a group of patients at highest $\mathrm{CV}$ risk and recommendations for their treatment should be based on this risk stratification. 
Which are the methods of risk assessment and prognostic stratification (also with respect to the existing comorbidities)?

\section{Screening for albuminuria}

Proteinuria has a twofold meaning. In patients with proteinuric nephropathy, the rate of progression of CKD is determined by arterial BP levels and the extent of proteinuria: the reduction of proteinuria and BP both have a beneficial effect on renal risk. Proteinuria is also a marker of systemic vascular damage and for this reason reducing proteinuria and controlling hypertension aim to improve $\mathrm{CV}$ risk and reduce the overall mortality. Measures of secondary prevention in patients with CKD should be extended to those at risk of progressive renal failure, even though they have never suffered from a known CKD. These subjects may be identified by screening for albuminuria. In addition to patients with diabetes hypertensive, obese and smokers are at risk of albuminuria. The assessment of patients with CKD can be carried out according to the values of GFR and albuminuria [according to the Kidney Disease: Improving Global Outcomes (KDIGO) classification of CKD: http://www.kdigo.org/clinical_practice_guidelines/pdf /CKD/KDIGO_2012_CKD_GL.pdf]. ${ }^{\overline{ }}$

It is recommended that in all patients with $\mathrm{CKD}$, in each of the five stages, has to be collected the medical history taking into account all CV risk factors, in order to implement all measures of cardiovascular disease secondary prevention. The following aspects must be explored: race and age; smoking and voluptuary habits; body weight; angina and myocardial infarction; previous coronary revascularization; stroke or transient cerebral ischemia; previous carotid surgery or angioplasty; peripheral vascular disease or previous vascular surgery; heart failure; arrhythmias; diabetes.

Which tailored actions shall be implemented for the individual patient?

\section{Non-pharmacological interventions}

Obesity is one of the risk factors for developing renal disease, and weight reduction programs can help patients in pre-dialysis to reduce proteinuria, blood pressure and the loss of kidney function. Physical activity combined with prescription of medications for obesity, together with dietary interventions up to bariatric surgery for severe obesity, can help to improve the eligibility of the transplanted kidney. Few data are available about peritoneal dialysis.

\section{Pharmacological prevention}

Both patients in 1-3 CKD and those in 4-5 stages (including patients on dialysis or renal transplanted) with a history of stable angina, acute coronary syn- drome, myocardial infarction, stroke, peripheral arterial disease, or those who are undergoing coronary surgery or revascularization angiography, should be treated with ASA, ACEi, $\beta$-blocker and statins, unless in the presence of contraindications to these drugs. ASA is indicated for secondary prevention of vascular disease in renal failure but not for the primary one. CV events are very common among patients with CKD disease and are significantly more frequent in patients on dialysis. The high number of CV events suggested some links between the increased total cholesterol or of LDL-c (responsible among the general population for causing atherosclerotic lesions) and $\mathrm{CV}$ death, but results are conflicting, furthermore any convincing reports that statins may improve outcomes were found. Despite several different opinions, 2011 ESC/EAS guidelines recommend their beneficial effect on the pathological proteinuria (if over $300 \mathrm{mg} /$ day) so that statins should be considered in patients in 2-4 CKD (class IIa, level of evidence B). ${ }^{16}$ Diabetes should be treated in accordance with the standards of care of the Italian Association of Diabetology Medical Doctors and the Italian Society of Diabetology (AMD-SID) $2014,{ }^{92}$ that include the use of last generation drugs, such as GLP1 analogues and DPP4 inhibitors. Comorbidities such as anemia should be corrected. Finally, we have to consider the use of drugs that can potentially aggravate renal function such as NSAID, diuretics, especially thiazides, the antagonists of aldosterone, ACEi and ARBs.

\section{Patients at high/very high cardiovascular risk for the concurrent presence of cardiac injury and renal failure}

In considering patients at high or very high $\mathrm{CV}$ risk we must refer to subjects who have already had a renal impairment as defined by KDIGO and those who had some myocardial damage leading to a deterioration of the cardiac function. A third category of patients are diabetic with kidney dysfunction. These patients can be classified in the cardio-renal syndrome (CRS), in particular the type II CRS (chronic cardiorenal), type IV (renal-chronic heart failure) and type $\mathrm{V}$ (renal failure secondary to systemic diseases like diabetes). Interactions between several organs may involve kidneys, heart, lungs, liver. In addition to the cardio-renal syndrome (and/or to the renal-cardiac syndrome), hepatorenal syndrome, the concept of cardio-pulmonary-renal syndrome is emerging. Considering the high mortality and the high rate of complications in patients with involvement of all three organs, an integrated approach for the identification of pathophysiological mechanisms involved, the identification of sensitive biomarkers is needed, through the collaboration of experts from various disciplines in order to improve the clinical condition and the survival of these patients. 


\section{Peripheral arterial disease}

Peripheral arterial disease (PAD),${ }^{93}$ defined as the presence of atherosclerotic occlusive vascular disease of the extremities, is a marker of systemic atherosclerosis, emerging as a strong risk factor for $\mathrm{CV}$ morbidity and mortality. Early diagnosis and aggressive medical therapy can significantly reduce $\mathrm{CV}$ risk profiles in such patients. PAD is a manifestation of systemic atherosclerosis, considered as a predictor for other types of cardiovascular disease (CVD) (CAD and/or cerebrovascular disease) and CVD events, such as myocardial infarction (MI), cerebrovascular accident, and death. ${ }^{94}$ Data from the REduction of Atherothrombosis for Continued Health $(\mathrm{REACH})$ registry are an interesting source of information about the risk of a subsequent vascular event in patients with PAD. It recorded 55,499 patients at baseline with symptomatic disease, of whom 39,675 were eligible for a 3-year follow up. Of these (at baseline): $6.3 \%$ (2485) had PAD only; 5.7\% (2271) had PAD plus CAD; $1.5 \%$ (614) had PAD plus cerebrovascular disease and 1.9\% (748) had PAD plus coronary artery disease plus cerebrovascular disease. Patients recruited to the trial with PAD had the highest 3-year event rate of MI/stroke/death/hospitalization $(40.4 \%)$. The hospital readmission rate for any vascular event was also higher for people with PAD (33.6\%), compared with $23 \%$ for those with CAD and $18.7 \%$ for patients with any cerebrovascular disease. Over the 3-year period, patients with only PAD at baseline had the highest risk of progressing to involvement of disease in another vascular bed. Almost $10 \%$ of patients with PAD progressed to polyvascular disease over 3 years compared with around $4 \%$ with either coronary artery disease or cerebrovascular disease at baseline. ${ }^{95}$ Total PAD prevalence, based on noninvasive testing, was $11.7 \%$, with increasing rates with age and elevated lipid levels. Despite strict guideline directives, the PAD is still considered today as undertreated in many countries. ${ }^{96}$

\section{Which are the methods of risk assessment and prognostic stratification (also with respect to the existing comorbidities)?}

Diagnosis of PAD begins by asking the patients about their medical history, symptoms experienced and their general health, smoking, or if they have high blood pressure and/or diabetes. The physical examination may reveal cold extremities and other signs of subclinical peripheral artery disease. More examples include bruits over blood vessels and lack of normal pulses, including those behind their knees and feet.

\section{Classification of peripheral arterial disease: clinical tools}

Scales in PAD assessment were implemented to allow clinicians to describe their patients, using a common terminology and standards for reports, dealing with lower extremity ischemia. ${ }^{97,98}$ Both the Rutherford and the Fontaine classifications are not used routinely in clinical practice, but rather more in research settings. However, as the 2005 ACC/AHA guidelines pointed out, they may be useful for standardized communication between clinicians ${ }^{99}$ (Appendix Table 4).

\section{Ankle-brachial index in adults in assessing peripheral arterial disease}

An ankle-brachial index in adults (ABI) is one of the most common tests that is used to diagnose PAD, comparing the person's blood pressure in their ankle with that in their arm. According to $2011 \mathrm{ACCF} / \mathrm{AHA}$ focused update recommendations the resting $A B I$ should be used to establish the lower extremity $P A D$ diagnosis in patients with suspected lower extremity $P A D$, defined as individuals with 1 or more of the following: exertional leg symptoms, non-healing wounds, age 65 years and older, or 50 years and older with a history of smoking or diabetes. ABI results should be uniformly reported with non-compressible values defined as greater than 1.40 , normal values 1.00 to 1.40 , borderline 0.91 to 0.99 , and abnormal 0.90 or less. ${ }^{100}$ Among patients with a low ABI (defined as $\leq 0.90$ ) detected in both population-based and high risk primary care cohorts, only 10-15\% have intermittent claudication. ${ }^{101,102}$ Moreover, the US Preventive Services Task Force (USPSTF) concluded that there is no sufficient evidence to define the balance of benefits and harms of screening for PAD and CVD risk assessment with the ABI in adults. The USPSTF found no evidence that screening for and treatment of PAD in asymptomatic patients leads to clinically important benefits. It also reviewed the potential benefits of adding the ABI to the $F R S$ and found evidence that this results in some patient risk reclassification; however, how often the reclassification is appropriate or whether it results in improved clinical outcomes is not known. ${ }^{11} \mathrm{ABI}$ could improve PAD risk assessment, without, however, any evidence about the question of whether measuring ABI leads to better patient outcomes. ${ }^{103}$

\section{Which tailored actions shall be implemented for the individual patient?}

Since PAD is a manifestation of systemic atherosclerosis in the lower extremities, its pharmacological therapeutic goals are nearly identical to those of the cerebrovascular disease and CVD. Smoking cessation, exercise, and an aggressive pharmacological CV risk factor modification, including diabetes, hypertension, lipid abnormalities, and life-long antiplatelet therapy, represent the cornerstones of treatment. For further details on each disease we refer to corresponding sections of this paper. 


\section{The role of exercise in peripheral artery disease}

Exercise therapy, combined with comprehensive secondary prevention, is very beneficial for patients with PAD, by preserving or improving functional capacity and reducing cardiovascular events. Effects of exercise include some potential mechanisms, such as increase in collateral flow, improved nitric oxide-dependent vasodilation and mitochondrial energetics, decreased systemic inflammation. ${ }^{104}$

\section{Antithrombotic therapy in peripheral artery disease}

According to 2012 ACCP guidelines for secondary prevention patients with symptomatic PAD, one of the two following antithrombotic regimens are recommended, to be continued long term over no antithrombotic treatment: ASA 75 to $100 \mathrm{mg}$ daily or clopidogrel $75 \mathrm{mg}$ daily (all Grade 1A). It is suggested not to use dual antiplatelet therapy with ASA plus clopidogrel (Grade 2B). For patients with intermittent claudication refractory to exercise therapy (and smoking cessation), the use of cilostazol in addition to previously recommended is suggested, while it is not advisable the use of pentoxifylline, heparinoids, or prostanoids (Grade 2C). Prostanoids are recommended in patients with symptomatic PAD and critical limb ischemia/rest pain who are not candidates for vascular intervention. For patients undergoing peripheral artery percutaneous transluminal angioplasty (PTA) with or without stenting, a long-term ASA ( $75-100 \mathrm{mg} /$ day) or clopidogrel ( $75 \mathrm{mg} /$ day) treatment is recommended (Grade 1A). For patients undergoing peripheral artery PTA with stenting, single rather than dual antiplatelet therapy is suggested. ${ }^{105}$ Despite these recommendations, the usefulness of ASA in preventing PAD is not so effective. ${ }^{106}$ The Antithrombotic Trialists' Collaboration meta-analysis demonstrates no benefit of ASA in reducing cardiovascular events in PAD. ${ }^{107}$ The effect of ASA on cardiovascular events in patients with preclinical PAD was studied in the Aspirin for Asymptomatic Atherosclerosis (AAA) trial with a double blind randomization of 3350 subjects with a low ABI $(\leq 0.95)$ and a follow up for 8.2 years. No statistically-significant difference in endpoints was found between the subjects treated with ASA $(100 \mathrm{mg})$ and the placebo group. ${ }^{108}$ Some new antiplatelet drugs, such as prasugrel, ticagrelor and picotamide seem to be more effective than ASA in PAD patients, particularly in diabetic patients with PAD. A novel antagonist of protease-activated receptor-1, vorapaxar, significantly reduced the rates of hospitalization for acute limb ischemia and peripheral artery revascularization. ${ }^{109}$

\section{Statins in peripheral artery disease}

Hypercholesterolemia, found in $45 \%$ to $59 \%$ of symptomatic PAD patients, is a relevant risk factor for PAD. Benefit of statin treatment on cardiovascular and cerebrovascular events has been shown in this group in PAD patients, in which additional effects of statins, such as improvement of pain-free walking distance and quality of life, have also been confirmed. ${ }^{110}$

\section{Quality of care in peripheral artery disease}

The list of quality statement developed for PAD in 2014 by the National Institute for Health and Care Excellence (NICE) ${ }^{111}$ is reported in Table 2.

\section{Diabetes mellitus}

Cardiovascular diseases are the leading cause of mortality and morbidity in diabetic patients, ${ }^{112}$ with an estimated reduction from 10 to 15 years of life expectancy at the age of 50 years.

Table 2. The National Institute for Health and Care Excellence list of quality statements for peripheral artery disease.

\begin{tabular}{l} 
Statement 1 \\
People who have symptoms of, or who are at risk of developing PAD are offered a clinical assessment and ankle brachial pressure index \\
measurement \\
\hline Statement 2 \\
People with PAD are offered an assessment for cardiovascular comorbidities and modifiable risk factors \\
Statement 3 \\
People with intermittent claudication are offered a supervised exercise program \\
Statement 4 \\
People with PAD being considered for revascularization who need further imaging after a duplex ultrasound are offered magnetic resonance \\
angiography
\end{tabular}

Statement 5

People with intermittent claudication are offered angioplasty only when imaging has confirmed it is appropriate, after advice on the benefits of modifying risk factors has been given and after a supervised exercise program has not improved symptoms

$\mathrm{PAD}$, peripheral arterial disease. 
Which are the methods of risk assessment and prognostic stratification (also with respect to the existing comorbidities)?

Diabetic patients with clinical or instrumental evidence of $\mathrm{CV}$ complications are considered at high/very high CV risk. Diabetic patients without clinical or instrumental evidence of cardiovascular complications are considered at high $\mathrm{CV}$ risk according to age ( $>40$ years), duration of diabetes and the presence of one or more other CV risk factors. Guidelines suggest a tailored approach to diabetic patients with high $\mathrm{CV}$ risk, taking into account their age, the severity of $\mathrm{CV}$ disease, the number and seriousness of comorbid conditions and the risk of iatrogenic hypoglycemia. ${ }^{113}$

\section{Which tailored actions shall be implemented for the individual patient?}

\section{Glycemic targets}

Tight glycemic control and glycated hemoglobin, preferably around $6.5 \%$, are indicated for newly diagnosed diabetic and/or young patients. Less stringent glycated hemoglobin (7.5-8\%) and less tight glucose control are recommended for diabetic patients with a long history of diabetes, in the elderly, mostly if frail and/or suffering from major comorbidities and/or frequent severe hypoglycemic events. Values for glycated hemoglobin much less tighter (8-9\%) are indicated for diabetic patients over eighty, mostly if losing their functional independence and/or at serious risk of hypoglycemia (Table 3 ).

\section{Lifestyle changes}

It is preferable not to aim for a diet but for an individualized nutritional therapy.

Physical activity is strongly recommended in diabetic patients. Regular exercise improves glycemic control and CV risk factors, facilitates weight loss, improves the subjective well-being.

\section{Associated clinical conditions \\ (for more details please refer to above paragraphs)}

Hypertension: ESH/ESC 2013 Guidelines recommended a target of $<140 / 85 \mathrm{~mm} \mathrm{Hg}$ for systolic BP (SBP) in diabetic patients, regardless of the level of $\mathrm{CV}$ risk (Recommendation grade IA).

Latest indications of 2015 the standard of care of the American Diabetes Association recommended for hypertensive diabetic patients a target of $<140 / 90$ (Level of Evidence: A). Lower targets $(<130 \mathrm{mmHg}$ $\mathrm{SBP},<80 \mathrm{mmHg}$ diastolic BP) may be pursued in some subjects (e.g., young subjects, with long life expectancy, or subjects to high risk of stroke - with high systolic arterial hypertension or with chronic kidney disease and albuminuria, with high diastolic arterial hypertension, hopefully achieved by the employment of few drugs without side effects.

Dyslipidemias: In secondary CV prevention statins should always be used at appropriate doses. Among the groups of patients considered to benefit the most from statin therapy there are specifically all the patients with diabetes aged 40-75 also without a history of clinical atherosclerotic CV disease and LDL-c of 70-189 mg/dL. ${ }^{13}$ Adding ezetimibe to simvastatin in diabetics with previous acute coronary syndrome is a good chance, according to the IMPROVE-IT trial. ${ }^{114}$

ASA and antiplatelet therapy: In primary prevention, therapy with ASA (75-162 mg/day) has to be taken into consideration in diabetic patients with a high $\mathrm{CV}(>10 \%$ at 10 years) (Strength of recommendation: $\mathrm{C}$ ). In diabetic patients with lower CV risk, therapy with ASA is not recommended, owing to the overwhelming bleeding risk $v s$ potential benefits. (Strength of recommendation: C). In secondary prevention ASA is strongly recommended (Strength of recommendation: A).

Table 3. Glycated hemoglobin targets in the secondary prevention in diabetic patients.

\begin{tabular}{|c|c|c|c|}
\hline $\begin{array}{c}\text { Clinical judgment } \\
\text { on the expectation of life } \\
\text { (years)* } \\
\text { This patient probably } \\
\text { will live }\end{array}$ & $\begin{array}{l}\text { Therapy only by drugs } \\
\text { at low risk of hypoglycemia }\end{array}$ & $\begin{array}{l}\text { Therapy by drugs at high } \\
\text { risk of hypoglycemia } \\
\text { In patients with good capacity } \\
\text { to self-management } \\
\text { (or in presence of } \\
\text { suitable caregivers) }\end{array}$ & $\begin{array}{l}\text { Therapy by drugs } \\
\text { at high risk of hypoglycemia }{ }^{\#} \\
\text { In patients with poor ability } \\
\text { to self-management } \\
\text { (or in absence of } \\
\text { suitable caregivers) }\end{array}$ \\
\hline$<5$ years & $<8 \%$ & $8-8.5 \%$ & $8-9 \% \S$ \\
\hline $5-10$ years & $<7 \%$ & $7-8 \%$ & $8-8.5 \% \S$ \\
\hline$>10$ years & $<7 \%$ & $<7 \%$ & $7-8 \%$ \\
\hline
\end{tabular}

*Based on age, severity of cardiovascular disease, number and seriousness of comorbid conditions; ${ }^{\circ}$ metformin, acarbose, DPP-IV (dipeptidyl peptidase 4) antagonists, GLP-1 (glucagon-like peptide 1 receptor) agonists, SGLT-2 (sodium-glucose co-transporter 2) inhibitors; ${ }^{*}$ sulfonylureas, glinides, insulin; ${ }^{\S}$ an A1C of $8.5 \%$ is equivalent to average estimated glucose of $200 \mathrm{mg} / \mathrm{dL}$; higher target involve further risks, related to glycosuria, dehydration and hyperglycemic hyperosmolar syndrome. 
Conclusions: in secondary prevention of Internal Medicine adult patients affected by atherosclerotic cardiovascular disease a comprehensive clinical judgment is needed

People with atherosclerotic cardiovascular disease have higher cardiovascular risk and need intensive lifestyle changes together with proactive pharmacological interventions. Risk stratification using risk charts is not required for making treatment decisions in them. ${ }^{115}$ Prevention is a great topic, that any modern health system cannot ignore. ${ }^{116}$ The discussion about the concept of CV prevention is very wide and lasts for a long time. In this context, the research has never been stopped. Today, in patients at very high $\mathrm{CV}$ risk, further therapeutic options will stand out, based on the use of monoclonal antiPCSK9. ${ }^{117,118}$ Moreover, the role of metformin ${ }^{119,120}$ and omega-3 is under discussion for the CV prevention in higher risk patients, even if the latter has not yet a proven efficacy in CAD. ${ }^{121}$ In achieving LDL$\mathrm{c}$ targets in $\mathrm{CV}$ prevention by statins it is required the following: a proper knowledge of the guidelines; the use of more effective statins according to their high, moderate or low intensity efficacy in lowering LDL$\mathrm{c},{ }^{13}$ increasing dosages of statins; the use of combination therapeutic strategies and greater attention to persistence in treatment by patients. Also recently the incremental usefulness of reducing LDL-c by adding ezetimibe to statin therapy in patients with previous acute coronary syndrome was confirmed. ${ }^{122}$ These results were particularly significant for patients with diabetes and CAD: in diabetics, the greatest reductions in CV events were in ischemic stroke (39\%), myocardial infarction (24\%), and the composite of death due to cardiovascular causes, myocardial infarction, or stroke $(20 \%)$. In diabetics and non-diabetics, there were no differences between ezetimibe and placebo in safety outcomes including liver test abnormalities, muscle side effects, gall bladder related events and cancer. In diabetics with recent acute coronary syndrome, ezetimibe added to simvastatin reduced LDL-c $(0.5 \mathrm{mmol} / \mathrm{L})(20 \mathrm{mg} / \mathrm{dL})$ more than simvastatin alone and achieved an average LDL-c of $1.4 \mathrm{mmol} / \mathrm{L}(54 \mathrm{mg} / \mathrm{dL})$, this greater reduction resulting in lower risks of future cardiovascular events. ${ }^{114}$ Medication therapy discontinuation after MI is common and occurs early after discharge. Patients who discontinue taking evidence-based medications are at increased mortality risk. ${ }^{123}$ Key determinants of CV care may not be the evidence, but rather some other variables, such as age, baseline comorbidity, kidney and liver function, disability, autonomy and dependency, social and local environmental factors, that can significantly influence the fitness/frailty of the real patient, its prognosis and therefore the doctor's decision making ${ }^{124}$ (Figure 1). ${ }^{13,125}$

\section{ASCVD assessment: a clinical judgment}

after overall clinical evaluation, associated morbidities (especially $\mathrm{CV}$ equivalents such as: diabetes, peripheral arterial disease, aortic aneurysm, chronic kidney disease, etc), anthropometric assessment, initial lab tests, echo-ultrasound examinations to investigate the state of the arteries

age $\leq 75$ yrs or even $>75$ yrs but: with good: excretory organs functions, fit and robust, not frail, functional status, life expectancy, low comorbidity index and risk of toxicity age $>75$ yrs

frail, old-old or very old, with poor functional status, low life expectancy, high comorbidity index, polypharmacy, and higher risk of toxicity

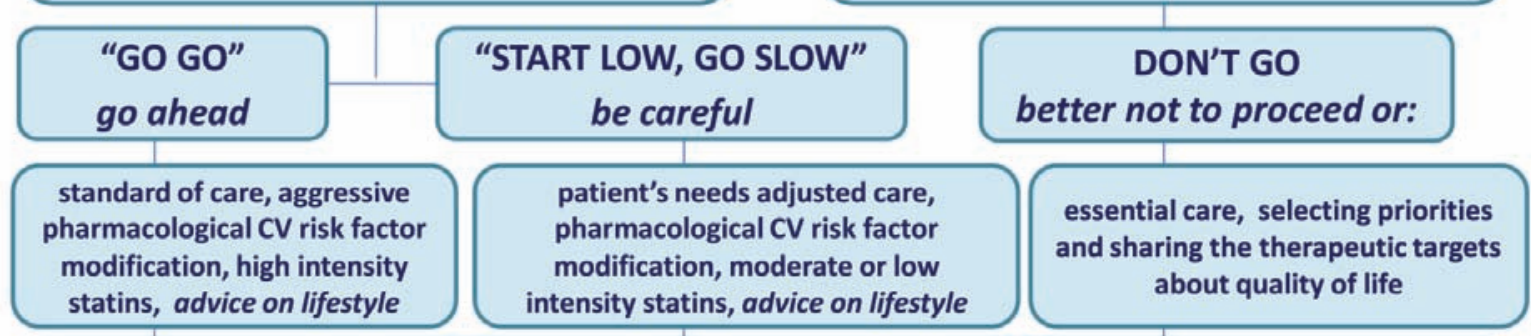

Involving the patient and its family in decision making, strict safety and adherence monitoring, medication reconciliation when necessary

Figure 1. General algorithm for reducing atherosclerotic cardiovascular disease (ASCVD) events in secondary CV risk prevention in Internal Medicine. Data from Wedding, $2003^{13}$ and Stone et al., 2013. ${ }^{125}$ 
A schematic classification of different types of prevention, as well as raised by the literature, implies obvious limitations, not always suitable to our complex patients. According to evidence based medicine we should refer to the best available guidelines. Unfortunately the evidence-based quality of guidelines is far from optimal, ${ }^{126}$ even when proposed by respectable scientific societies, because in most cases trials excluded patients deriving from the real world. Guidelines do not consider complex circumstances, thus being unsuitable, because of the lack of evidence. Although recently it has begun to consider the problem of comorbidities, there are few guidelines that consider that some patients may be suffering from other concomitant diseases, and treated with further drugs ${ }^{127,128}$ with risk of drug interactions and adverse reactions, ${ }^{129,130}$ such as in case of multiple antihypertensive therapy. ${ }^{131}$ We have to recognize that to date no satisfactory evidence based guidelines for complex patients are available. We always need a careful judgment on any single case, before applying the general indications of guidelines. ${ }^{132,133}$ For the purposes of a $\mathrm{CV}$ risk evaluation in complex patient we cannot be satisfied with a single high baseline risk strategy: we should resize our assessment parameters to the real world, implementing a high multidimensional $\mathrm{CV}$ complexity risk assessment strategy, in respect of an anthropological approach to the complexity of our patients. ${ }^{134}$ Essentially, hospital internists are called to exercise a proactive role of experts for each single complex patient, also in CV prevention. ${ }^{135}$ The peculiarity of the internists is to know how to face - with a systemic vision - the cases of higher $\mathrm{CV}$ risk, deserving specific assessment, prevention and treatment in each selected case. ${ }^{136}$ We need to identify the levels of $\mathrm{CV}$ risk in the individual patient by a multidimensional assessment, with a careful selection of the existing priorities, as well as the evaluation of the actual adherence to effective therapies, a systematic exercise of reconciliation in each therapeutic opportunity care, counseling and implementing the best appropriate treatment. ${ }^{137}$

\section{References}

1. Davis MA, Bynum JPW, Sirovich BE. Association between apple consumption and physician visits: appealing the conventional wisdom that an apple a day keeps the doctor away. JAMA Intern Med 2015;175:777-83.

2. Nardin C, Rattazzi M, Pauletto P. La patogenesi dell'aterosclerosi. Quad Ital J Med 2015 [In press].

3. Puato MFE, Pauletto P, Pessina AC. La malattia aterosclerotica. In: Crepaldi G, Baritussio A, eds. Malattie del cuore e dei vasi. Padova: Editore Piccin; 2002. pp 2753-2780.

4. Stary HC, Chandler AB, Glagov S, et al. A definition of initial, fatty streak, and intermediate lesions of athero- sclerosis. A report from the Committee on Vascular Lesions of the Council on Arteriosclerosis, American Heart Association. Arterioscler Thromb 1994;14:840-56.

5. Last JM. A Dictionary of epidemiology, 3rd ed. Oxford: Oxford University Press; 1995.

6. World Health Organization. Prevention of cardiovascular disease - guidelines for assessment and management of cardiovascular risk. Geneva: WHO; 2007. Available from: http://www.who.int/cardiovascular_diseases/ guidelines/Full\%20text.pdf

7. Koenig W. Update on integrated biomarkers for assessment of long-term risk of cardiovascular complications in initially healthy subjects and patients with manifest atherosclerosis. Ann Med 2009;41:332-43.

8. Pearson T. New tools for coronary risk assessment what are their advantages and limitations? Circulation 2002; 105:886-92.

9. Perk J, De Backer G, Gohlke H, et al. European Guidelines on cardiovascular disease prevention in clinical practice. The Fifth Joint Task Force of the European Society of Cardiology and Other Societies on Cardiovascular Disease Prevention in Clinical Practice (constituted by representatives of nine societies and by invited experts. Eur Heart J 2012;33:1635-701.

10. Comunicato congiunto da parte di ANMCO, FIC, SIC e SISA. Nuove linee guida americane 2013 ACC/AHA Guidelines on the treatment of blood cholesterol to reduce atherosclerotic cardiovascular risk: Confronto con le raccomandazioni EAS/ESC per la gestione delle dislipidemie. Available from: http://www.sisa.it/upload/Comunicato_Congiunto_lineeguida_EAS_USA.pdf

11. Goff DC Jr, Lloyd-Jones DM, Bennett G, et al. 2013 ACC/AHA guideline on the assessment of cardiovascular risk: a report of the American College of Cardiology/American Heart Association Task Force on Practice Guidelines. Circulation 2014;129:S49-73.

12. Eckel RH, Jakicic JM, Ard JD, et al. 2013 AHA/ACC guideline on lifestyle management to reduce cardiovascular risk: a report of the American College of Cardiology/American Heart Association Task Force on Practice Guidelines. J Am Coll Cardiol 2014;63:2960-84.

13. Stone NJ, Robinson J, Lichtenstein AH, et al. 2013 ACC/AHA guideline on the treatment of blood cholesterol to reduce atherosclerotic cardiovascular risk in adults: a report of the American College of Cardiology/American Heart Association Task Force on Practice Guidelines. Circulation 2014;129:S1-45.

14. Vandvik PO, Lincoff AM, Gore JM, et al. Primary and secondary prevention of cardiovascular disease: antithrombotic therapy and prevention of thrombosis, 9th ed: American College of Chest Physicians EvidenceBased Clinical Practice Guidelines. Chest 2012;141: e637S-68S.

15. Genest J, McPherson R, Frohlich J, et al. 2009 Canadian Cardiovascular Society/Canadian guidelines for the diagnosis and treatment of dyslipidemia and prevention of cardiovascular disease in the adult - 2009 recommendations. Can J Cardiol 2009;25:567-79.

16. ESC/EAS Guidelines for the management of dyslipidaemias: the task force for the management of dyslipidaemias of the European Society of Cardiology (ESC) and the European Atherosclerosis Society (EAS). Atherosclerosis 2011;217S:S1-S44. 
17. Virani SS. What is new in the 2013 ACC/AHA guideline on the treatment of blood cholesterol to reduce atherosclerotic risk in adults? Texas Heart Inst J 2014;41:304-5.

18. Boyd CM, Leff B, Wolff JL, et al. Informing clinical practice guideline developement and implementation: prevalence of coexisting conditions among adults with coronary heart disease. J Am Geriatr Soc 2011;59:797.

19. Nardi R, Nozzoli C, Frasson S, et al. Development of a new predictive model to evaluate the complexity of patients hospitalized in Internal Medicine (IM). The FADOI-COMPLIMED Study. Ital J Med 2015 [In press].

20. Di Rosa S, Iori I, Vescovo G, et al. Trends in cardiovascular risk factors and their treatment among patients discharged from divisions of internal medicine. The FAPOI-1 and FADOI-2 studies. Ital Heart J 2003;4: 460-7.

21. Nardi R, Blasi I, Alduino R, et al. Sindrome metabolica nei pazienti ricoverati in Medicina Interna: risultati dello studio pilota NIMEC (National Internal Medicine Equivalent/Complex C-V-@Risk). Ital J Med 2007; 1:21-31.

22. Gussoni G. Presentazione dei dati preliminari al Consiglio Direttivo FADOI, sulla "Giornata Nazionale della Medicina Interna - Un Metro per la Vita, 7 Giugno 2015", 17 settembre 2015, Bologna, Italy.

23. Nardi R, Scanelli G, Borioni D, et al. The assessment of complexity in internal medicine patients. The FADOI Medicomplex Study. Eur J Intern Med 2007;18:283-7.

24. Micheel CM, Ball JR, ed. Evaluation of biomarkers and surrogate endpoints in chronic disease. Washington, DC: The National Academies Press; 2010. Available from: http://www.iom.edu/Reports/2010/Evaluation-of-Biomarkers-and-Surrogate-Endpoints-in-Chronic-Disease. aspx

25. Fleming TR, Powers JH. Biomarkers and surrogate endpoints in clinical trials. Stat Med 2012;31:2973-84.

26. Zulman DM, Asch SM, Martins SB, et al. Quality of care for patients with multiple chronic conditions: the role of comorbidity interrelatedness. J Gen Intern Med 2013;29:529-37.

27. Fabbri LM, Luppi F, Beghé B, Rabe KF. Complex chronic comorbidities of COPD. Eur Respir J 2008;31: 204-12.

28. Nozzoli C, Beghè B, Boschetto P, Fabbri LM. Identifying and treating COPD in cardiac patients. Chest 2013;144:723-6.

29. Townsend P, Phillimore P, Beattie A. Health and deprivation: inequality and the north. London: Routledge; 1988.

30. Aryal S, Diaz-Guzman E, Mannino DM. Epidemiology of comorbidities in chronic obstructive pulmonary disease: clusters, phenotypes and outcomes. Ital J Med 2012;6:276-84.

31. Cartabellotta A, Accettura L, Santoiemma L. Linee guida per la valutazione del rischio cardiovascolare e la terapia ipocolesterolemizzante. Evidence 2015;7:e1000106.

32. Zhu JA, Halcox JP, Waclawiw MA, et al. Predisposition to atherosclerosis by infections: role of endothelial dysfunction. Circulation 2002;106:184-90.

33. Mendy A, Vieira ER, Gasana J. Seropositivity to herpes simplex virus type 2, but not type 1 is associated with premature cardiovascular diseases: a population-based cross-sectional study. Atherosclerosis 2013;231:18-21.
34. Jitsuiki K, Yamane K, Nakajima M, et al. Association of Chlamydia pneumoniae infection and carotid intimamedia wall thickness in Japanese Americans. Circ J 2006;70:815-9.

35. Ng B, Macpherson P, Haddad T, Dwivedi G. Heart failure in HIV infection: focus on the role of atherosclerosis. Curr Opin Cardiol 2014;29:174-9.

36. Baker JV, Lundgren JD. Cardiovascular implications from untreated human immunodeficiency virus infection. Eur Heart J 2011;32:945-51.

37. Oliveira CP, Kappel CR, Siqueira ER, et al. Effects of hepatitis $\mathrm{C}$ virus on cardiovascular risk in infected patients: a comparative study. Int J Cardiol 2013;164:221-6.

38. Wubiee F, Howell C. Hepatitis C infection is associated with an increase in cardiovascular diseases. Presented at the International Liver Congress, Vienna, Austria. Available from: https://ilc-congress.eu/programmeebook/files/basic-html/page250.html

39. Venkata N, Pothineni KC, Delongchamp R, et al. Impact of hepatitis $\mathrm{C}$ seropositivity on the risk of coronary heart disease events. Am J Cardiol 2014;114:1841-5.

40. Beltowski J. Leptin and atherosclerosis. Atherosclerosis 2006;189:47-60.

41. Minelli M, Arsieni A, Iadarola G, et al. Rapporto IMID 2007: Documento di base sulla possibile adozione di un modello pluridisciplinare integrato nelle malattie croniche immunomediate. South Immunol J 2007;2/3:32-43.

42. Martin SS, Abd TT, Jones SR, et al. 2013 ACC/AHA cholesterol treatment guidelinewhat was done well and what could be done better. J Am Coll Cardiol 2014;63:2674-8.

43. Expert Panel on Detection, Evaluation, and Treatment of High Blood Cholesterol in Adults. Executive summary of the third report of the National Cholesterol Education Program (NCEP) Expert Panel on Detection, Evaluation, and Treatment of High Blood Cholesterol in Adults (Adult Treatment Panel III). JAMA 2001;285:2486-97.

44. Grundy SM, Cleeman JI, Bairey Merz CN, et al. Implications of recent clinical trials for the National Cholesterol Education Program Adult Treatment Panel III guidelines. Circulation 2004;110:227-39.

45. National Cholesterol Education Program (NCEP) Expert Panel on Detection, Evaluation, and Treatment of High Blood Cholesterol in Adults (Adult Treatment Panel III). Third report of the National Cholesterol Education Program (NCEP) expert panel on detection, evaluation, and treatment of high blood cholesterol in adults (Adult Treatment Panel III). Final report. Circulation 2002;106:3143-421.

46. Jensen GL. Inflammation: roles in aging and sarcopenia. JPEN J Parenter Enteral Nutr 2008;32:656-9.

47. Dominguez LJ, Barbagallo M. The cardiometabolic syndrome and sarcopenic obesity in older persons. JCMS 2007;2:183-9.

48. Hales CN, Barker DJ. The thrifty phenotype hypothesis. Br Med Bull 2001;60:5-20.

49. Guardamagna O, Abello F, Cagliero P, Lughetti L. Impact of nutrition since early life on cardiovascular prevention. Ital J Pediatr 2012;38:73.

50. Sipola-Leppnen M, Karvonen R, Tikanmk MI, Matinolli $\mathrm{HM}$. Ambulatory blood pressure and its variability in adults born preterm. Hypertension 2015;65:615-21.

51. Fedi A, Cipollini F, Arcangeli E, et al. Should low birth- 
weight be considered a relevant risk factor for rise in pulse pressure among adult overweight-obese subjects? Ital J Med 2015;9:273-8.

52. Foley RN, Parfrey PS, Sarnak MJ. Clinical epidemiology of cardiovascular disease in chronic renal disease. Am J Kidney Dis 1998;32:S112-9.

53. Corsonello A, Pedone C, Lattanzio F, et al. Does concealed chronic kidney disease predict survival of older patients discharged from acute care hospitals? Rejuvenation Res 2010;13:539-45.

54. Angelico F, del Ben M, Augelletti T, et al. Obstructive sleep apnoea syndrome and the metabolic syndrome in an internal medicine setting. Eur J Intern Med 2010;21:191-5.

55. Artom N, Pinna G. The erectile dysfunction as a cardiovascular risk factor. Ital J Med 2014;8:210-20.

56. Corrales-Medina VF, Alvarez KN, Weissfeld LA, et al. Association between hospitalization for pneumonia and subsequent risk of cardiovascular disease. JAMA 2015;313:264-74.

57. Garnick MB. Testosterone replacement therapy faces FDA scrutiny. JAMA 2015;316:563-4.

58. US Food and Drug Administration. 2014 Meeting materials of the bone, reproductive, and urologic drugs advisory committee (formerly Advisory Committee for Reproductive Health Drugs (ACRHD)). Available from: http://www.fda.gov/AdvisoryCommittees/CommitteesMeetingMaterials/Drugs/ReproductiveHealthDrugsAdvisoryCommittee/ucm404895.htm Accessed: November 20, 2014.

59. Witham MD, Ireland S, Houston JG, et al. Vitamin D therapy to reduce blood pressure and left ventricular hypertrophy in resistant hypertension randomized, controlled trial. Hypertension 2014;63:706-12.

60. Montagnani A, Nardi R, Cercignani M, Verdiani V. Potential role of vitamin $\mathrm{D}$ in prevention of skeletal and extraskeletal diseases in older people. Ital J Med 2015 [In press].

61. Bahekar AA, Singh S, Saha S, et al. The prevalence and incidence of coronary heart disease is significantly increased in periodontitis: a meta-analysis. Am Heart J 2007;154:830-7.

62. Dietrich T, Sharma P, Walter C, et al. The epidemiological evidence behind the association between periodontitis and incident atherosclerotic cardiovascular disease. J Periodontol 2013;84:S70-84.

63. Panuccio D, Verdecchia P. La prevenzione secondaria nella cardiopatia ischemica. Quad Ital J Med 2015 [In press].

64. Kotseva K, Wood D, De Backer G, et al. EUROASPIRE III: a survey on the lifestyle, risk factors and use of cardioprotective drug therapies in coronary patients from 22 European countries. Eur J Cardiovasc Prev Rehabil 2009;16:121-37.

65. Dusseldorp E, van Elderen T, Maes S, et al. A metaanalysis of psychoeduational programs for coronary heart disease patients. Health Psychol 1999;18:506-19.

66. He J, Vupputuri S, Allen K, et al. Passive smoking and the risk of coronary heart disease--a meta-analysis of epidemiologic studies. N Engl J Med 1999;340:920-6.

67. Astrup A, Dyerberg J, Elwood P, et al. The role of reducing intakes of saturated fat in the prevention of cardiovascular disease: where does the evidence stand in 2010? Am J Clin Nutr 2011;93:684.
68. Berrington de Gonzalez A, Hartge P, Cerhan JR, et al. Body-mass index and mortality among 1.46 million white adults. N Engl J Med 2010;363:2211-9.

69. Zanchetti A, Grassi G, Mancia G. When should antihypertensive drug treatment be initiated and to what levels should systolic blood pressure be lowered? A critical reappraisal. J Hypertens 2009;27:923-34.

70. Piepoli MF, Corra U, Benzer W, et al. Secondary prevention through cardiac rehabilitation: from knowledge to implementation. A position paper from the Cardiac Rehabilitation Section of the European Association of Cardiovascular Prevention and Rehabilitation. Eur J Cardiovasc Prev Rehabil 2010;17:1-17.

71. Viberti G, Wheeldon NM. Microalbuminuria reduction with valsartan in patients with type 2 diabetes mellitus: a blood pressure-independent effect. Circulation 2002; 106:672-8.

72. Jardine MJ, Ninomiya T, Perkovic V, et al. Aspirin is beneficial in hypertensive patients with chronic kidney disease: a post-hoc subgroup analysis of a randomized controlled trial. J Am Coll Cardiol 2010;56:956-65.

73. de Lemos JA, Blazing MA, Wiviott SD, et al. Early intensive vs a delayed conservative simvastatin strategy in patients with acute coronary syndromes: phase $\mathrm{Z}$ of the A to Z trial. JAMA 2004;292:1307-16.

74. [No authors listed]. Effect of intensive blood-glucose control with metformin on complications in overweight patients with type 2 diabetes (UKPDS 34). UK Prospective Diabetes Study (UKPDS) Group. Lancet 1998;352: 854-65.

75. [No authors listed]. Intensive blood-glucose control with sulphonylureas or insulin compared with conventional treatment and risk of complications in patients with type 2 diabetes (UKPDS 33). UK Prospective Diabetes Study (UKPDS) Group. Lancet 1998;352:837-53.

76. [No authors listed]. Effect of intensive blood-glucose control with metformin on complications in overweight patients with type 2 diabetes (UKPDS 34). Lancet 1998;352:854-65.

77. Cavaliere R, Gallucci F, Mathieu G. La prevenzione cardiovascolare nello scompenso cardiaco. Quad Ital J Med 2015 [In press].

78. Braunwald E. Heart failure: an overview. New York: Mc Graw Hill; 1997.

79. Yancy CW, Jessup M, Bozkurt B, et al. 2013 ACCF/AHA Guideline for the management of heart failure: a report of the American College of Cardiology Foundation/American Heart Association Task Force on Practice Guidelines. Circulation 2013;128:1810-52.

80. The Criteria Committee of the New York Heart Association. Nomenclature and criteria for diagnosis of diseases of the heart and great vessels. 9th ed. Boston: Little, Brown \& Co.; 1994. pp 253-256.

81. Friedrich EB, Böhm M. Management of end stage heart failure. Heart 2007;93:626-31.

82. Moss AJ, Hall WJ, Cannom DS, et al. Cardiac resynchronization therapy for the prevention of heart-failure events. N Engl J Med 2009;361:1329-38.

83. Tang AS, Wells GA, Talajic M, et al. Cardiac-resynchronization therapy for mild-to-moderate heart failure. $\mathrm{N}$ Engl J Med 2010;363:2385-95.

84. Miller LW, Guglin M. Patient selection for ventricular assist devices: a moving target. J Am Coll Cardiol 2013; 61:1209-21. 
85. Paciaroni M, Frediani R, Stornello M, Agnelli G. Prevenzione secondaria degli eventi cerebrovascolari aterotrombotici.Quad Ital J Med 2015 [In press].

86. Rajamani K, Chaturvedi S. Stroke prevention-surgical and interventional approaches to carotid stenosis. Neurotherapeutics 2011;8:503-14.

87. Brott TG, Halperin JL, Abbara S, et al. 2011 ASA/ACCF/AHA/AANN/AANS/ACR/ASNR/CNS/S AIP/SCAI/SIR/SNIS/SVM/SVS guideline on the management of patients with extracranial carotid and vertebral artery disease. A report of the American College of Cardiology Foundation/American Heart Association Task Force on Practice Guidelines, and the American Stroke Association, American Association of Neuroscience Nurses, American Association of Neurological Surgeons, American College of Radiology, American Society of Neuroradiology, Congress of Neurological Surgeons, Society of Atherosclerosis Imaging and Prevention, Society for Cardiovascular Angiography and Interventions, Society of Interventional Radiology, Society of NeuroInterventional Surgery, Society for Vascular Medicine, and Society for Vascular Surgery. Circulation 2011;124:e54-130.

88. Sorensen AG, Ay H. Transient ischemic attack definition, diagnosis, and risk stratification. Neuroimaging Clin N Am 2011;21:303-13.

89. Rothwell PM, Gutnikov SA, Warlow CP. Reanalysis of the final results of the European Carotid Surgery Trial. Stroke 2003;34:514-23.

90. Manfellotto D, Vescovo G. Prevenzione cardiovascolare secondaria e nefropatia. Quad Ital J Med 2015 [In press].

91. Kidney Disease: Improving Global Outcomes (KDIGO) CKD Work Group. KDIGO clinical practice guideline for the evaluation and management of chronic kidney disease. Kidney Intern Suppl 2013;3:1-150.

92. Frontoni S, Lapolla A, Ponziani MC, De Micheli A. Standard Italiani 2.0 AMD-SID standard italiani per la cura del diabete mellito 2014. Il Diabete 2014;26:148-54.

93. Dentali F, Mazzone A. Arteriopatia obliterante periferica cronica degli arti inferiori. Quad Ital J Med 2015 [In press].

94. Lin S, Olson C, Johnson E, et al. Screening for peripheral artery disease with ankle brachial index testing: a systematic evidence review for the U.S. Preventive Services Task Force. Evidence Synthesis No. 100. AHRQ Publication No. 12-05162-EF-1. Rockville, MD: Agency for Healthcare Research and Quality; 2013.

95. Alberts M, Bhatt D, Mas J, et al. Three-year follow-up and event rates in the international reduction of atherothrombosis for continued health registry. Eur Heart J 2009;30:2318-26.

96. Muller-Buhl U, Laux G, Szecsenyi J. Secondary pharmacotherapeutic prevention among german primary care patients with peripheral arterial disease. Int J Vasc Med 2011;2011:316496.

97. Becker F. La classification de l'insuffisance artérielle des membres inférieurs de Leriche et Fontaine: une réactualisation nécessaire. Méd Hyg 1991;49:143-9.

98. Rutherford RB, Baker JD, Ernst C, et al. Recommended standards for reports dealing with lower extremity ischemia: revised version. J Vasc Surg 1997;26:517-38.

99. Hirsch AT, Haskal ZJ, Hertzer NR, et al. ACC/AHA 2005 Practice Guidelines for the management of patients with peripheral arterial disease (lower extremity, renal, mesenteric, and abdominal aortic): a collaborative report from the American Association for Vascular Surgery/Society for Vascular Surgery, Society for Cardiovascular Angiography and Interventions, Society for Vascular Medicine and Biology, Society of Interventional Radiology, and the ACC/AHA Task Force on Practice Guidelines (Writing Committee to Develop Guidelines for the Management of Patients With Peripheral Arterial Disease): endorsed by the American Association of Cardiovascular and Pulmonary Rehabilitation; National Heart, Lung, and Blood Institute; Society for Vascular Nursing; TransAtlantic Inter-Society Consensus; and Vascular Disease Foundation. Circulation 2006; 113:e463-654.

100. Rooke TW, Hirsch AT, Misra S, et al. 2011 ACCF/AHA Focused Update of the Guideline for the Management of Patients With Peripheral Artery Disease (Updating the 2005 Guideline): A Report of the American College of Cardiology Foundation/American Heart Association Task Force on Practice Guidelines. Circulation 2011;124:2020-45.

101. Feigelson HS, Criqui MH, Fronek A, et al. Screening for peripheral arterial disease: the sensitivity, specificity, and predictive value of noninvasive tests in a defined population. Am J Epidemiol 1994;140:526-34.

102. Hirsch AT, Criqui MH, Treat-Jacobson D, et al. Peripheral arterial disease detection, awareness, and treatment in primary care. JAMA 2001;286:1317-24.

103. Moyer VA, on behalf of the U.S. Preventive Services Task Force. Screening for peripheral artery disease and cardiovascular disease risk assessment with the anklebrachial index in adults: U.S. Preventive Services Task Force Recommendation Statement. Ann Intern Med 2013;159:342-8.

104. Hamburg NM, Baldy GJ. Exercise rehabilitation in peripheral artery disease: functional impact and mechanisms of benefits. Circulation 2014;123:87-97.

105. Alonso-Coello P, Bellmunt S, McGorrian C, et al. Antithrombotic therapy in peripheral artery disease: antithrombotic therapy and prevention of thrombosis, 9th ed: American College of Chest Physicians EvidenceBased Clinical Practice Guidelines. Chest 2012;141: e669S-90S.

106. Poredos P, Jezovnik MK. Do the effects of secondary prevention of cardiovascular events in PAD patients differ from other atherosclerotic disease? Int J Mol Sci 2015; 16:14477-89.

107. Baigent C, Blackwell L, Collins R, et al. Aspirin in the primary and secondary prevention of vascular disease: collaborative meta-analysis of individual participant data from randomised trials. Lancet 2009;373:1849-60.

108. Fowkes FG, Price JF, Stewart MC, et al. Aspirin for prevention of cardiovascular events in a general population screened for a low ankle brachial index: a randomized controlled trial. JAMA 2010;303:841-8.

109. Bonaca MP, Scirica BM, Creager MA, et al. Vorapaxar in patients with peripheral artery disease results from TRA $2{ }^{\circ}$ P-TIMI 50. Circulation 2013;127:1522-9.

110. Heart Protection Study Collaborative Group. $\mathrm{MRC} / \mathrm{BHF}$ heart protection study of cholesterol lowering with simvastatin in 20,536 high-risk individuals: a randomised placebo-controlled trial. Lancet 2002; 360:7-22. 
111. National Institute for Health Care and Excellence (NICE). Peripheral arterial disease - Issued: January 2014. NICE quality standard 52. Available From: http://www.nice.org.uk/guidance/qs52

112. Augello G, Magnani L. La prevenzione cardiovascolare secondaria nel paziente con diabete mellito. Quad Ital J Med [In press].

113. Canadian Diabetes Association. Canadian guidelines for the assessment of medical fitness in pilots, flight engineers and air traffic controllers with diabetes mellitus. CJD 2013;161(11 Suppl). Available from: https:// www.tc.gc.ca/eng/civilaviation/publications/tp133122-diabetes-guidelines-2375.htm

114. Giugliano RP. Benefit of adding ezetimibe to statin therapy on cardiovascular outcomes and safety in patients with vs without diabetes: the IMPROVE-IT Trial, at Clinical Trial Update 1 - Cardiovascular diseases: prevention, outcomes, quality. ESC Congress, $30 \mathrm{Au}-$ gust 2015, London, UK.

115. World Health Organization. Prevention of cardiovascular disease pocket guidelines for assessment and management of cardiovascular risk. Geneva: WHO; 2007.

116. Iacobucci G. NHS plan calls for new models of care and greater emphasis on prevention. BMJ 2014;349: g6430.

117. Robinson JG, Farnier M, Krempf M, et al. Efficacy and safety of alirocumab in reducing lipids and cardiovascular events. N Engl J Med 2015;372:1489-92.

118. Sabatine MS, Giugliano RP, Wiviott SD, et al. Efficacy and safety of evolocumab in reducing lipids and cardiovascular events. N Engl J Med 2015;372:1500-9.

119. The Diabetes Prevention Program Research Group. Impact of intensive lifestyle and metformin therapy on cardiovascular disease risk factors in the diabetes prevention program. Diabet Care 2005;28:888-94.

120. Home P. Cardiovascular disease and oral agent glucoselowering therapies in the management of type 2 diabetes. Diabet Technol Ther 2012;Suppl 1:S33-42.

121. Mazza A. PUFA Omega-3 e rischio cardiovascolare: dalla teoria alla pratica. Available from: http://www. fadoi.org/allegato_news/1259_Newsletter_FADOI_IB SA_PUFA.pdf

122. Cannon CP, Blazing MA, Giugliano RP, et al. Ezetimibe added to statin therapy after acute coronary syndromes. N Engl J Med 2015;372:2387-97.

123. Ho PM, Spertus JA, Masoudi FA, et al. Impact of medication therapy discontinuation on mortality after myocardial infarction. Arch Intern Med 2006;166:1842-7.

124. Kaul P, Peterson ED. The cardiovascular world is definitely not flat. Circulation 2007;115:158-60.
125. Wedding U. Endpoints and their relevance to older people, cancer and palliative care and work of EORTC, Elderly Task Force EORTC, 22th March 2012, Brussels. Available from: http://www.ema.europa.eu/docs/ en_GB/document_library/Presentation/2012/04/WC50 0125115.pdf

126. Tricoci P, Allen JM, Kramer JM, et al. Scientific evidence underlying the ACC/AHA clinical practice guidelines. JAMA 2009;301:831-41.

127. Tinetti ME, McAvay G, Trentalange M, et al. Association between guideline recommended drugs and death in older adults with multiple chronic conditions: population based cohort study. BMJ 2015;351:h4984.

128. Muth C, Glasziou PP. Guideline recommended treatments in complex patients with multimorbidity. BMJ 2015;351:h5145.

129. Wise J. Polypharmacy: a necessary evil. BMJ 2013; 347:f7033.

130. Dumbreck S, Flynn A, Nairn M, et al. Drug-disease and drug-drug interactions: systematic examination of recommendations in 12 UK national clinical guidelines. BMJ 2015;350:h949.

131. Benetos A, Labat C, Rossignol P, et al. Treatment with multiple blood pressure medications, achieved blood pressure, and mortality in older nursing home residents. The PARTAGE Study. JAMA Intern Med 2015; 175:989-95.

132. [No authors listed]. When clinical practice guidelines fail. Lancet 2005;365:1440.

133. Grimshaw J, Eccles M, Thomas R, et al. Toward evidence-based quality improvement, evidence (and its limitations) of the effectiveness of guideline dissemination and implementation, strategies 1966-1998. J Gen Intern Med 2006;21:S14-20.

134. Campanini M. La Medicina Interna ospedaliera: tra complessità ed intensità assistenziale verso una medicina sostenibile. Quad Ital J Med 2014;2:1-2.

135. Beresford L. The role of hospitalists in preventive medicine. Medscape 2015. Available from: http://www. medscape.com/viewarticle/839159_print

136. UK Department of Health - DH Cardiovascular Disease Team. Cardiovascular disease outcomes strategy - improving outcomes for people with or at risk of cardiovascular disease; 2013. Available from: https:/www.gov.uk/ government/uploads/system/uploads/attachment_data/file /217118/9387-2900853-CVD-Outcomes_web1.pdf

137. Zuccheri P, Manfredi F, Serra A, et al. Medication reconciliation as a tool for reducing polypharmacy at hospital discharge in Internal Medicine Wards. Ital J Med 2014;8:232-7. 